\title{
POLÍTICAS PÚBLICAS DE ENFRENTAMENTO À VIOLÊNCIA CONTRA MULHERES E MENINAS NO BRASIL RECENTE: ANÁLISE DOS MOVIMENTOS FEMINISTAS NO PROCESSO DE AFIRMAÇÃO DE DIREITOS
}

Ana Paula Antunes Martins ${ }^{1}$

Resumo: O advento da Lei Maria da Penha (Lei 11.340/2006) e da Lei do Feminicídio (Lei 13.104/2015) no Brasil representa um marco no processo de institucionalização das políticas de enfrentamento à violência doméstica e familiar e das ações de atendimento às mulheres atingidas. A análise da legislação brasileira, considerada referência internacional de garantia dos direitos humanos das mulheres, requer a compreensão de sua historicidade que envolve, necessariamente, a trajetória de controvérsias, lutas e mobilizações internacionais gestadas por distintos setores da sociedade civil. O presente artigo recupera, portanto, alguns dos mais importantes documentos internacionais que subsidiaram a formulação das políticas públicas brasileiras e analisa os fundamentos legais para a promoção de políticas públicas de equidade de gênero mesmo em contextos de retração de direitos. Objetiva-se, com isso, enfatizar a afirmação de direitos como um processo político marcado não apenas por avanços, mas por resistências e profundos desafios.

Palavras-chave: Direitos das mulheres e meninas; políticas públicas; tratados e convenções internacionais; movimentos feministas.

\begin{abstract}
The advent of the Maria da Penha Law (Law 11.340 / 2006) and the Law on Feminicide (Law 13.104 / 2015) in Brazil represent a milestone in the process of institutionalizing policies to deal with domestic and family violence and actions to provide care to affected women. The analysis of Brazilian legislation, considered an international reference for guaranteeing the human rights of women, requires an
\end{abstract}

\footnotetext{
${ }^{1}$ Doutora em Sociologia (UnB). Graduada em Direito (FURG). Pesquisadora do Núcleo de Estudos e Pesquisas sobre as Mulheres (NEPeM/UnB). Professora Substituta no Departamento de Gestão de Políticas Públicas (GPP/UnB).
} 
understanding of its historicity, which necessarily involves the trajectory of international controversies, struggles and mobilizations developed by different sectors of civil society. This article therefore retrieves some of the most important international documents that have subsidized the formulation of Brazilian public policies and analyzes the legal foundations for the promotion of public policies of gender equality even in contexts of retraction of rights. The objective is to emphasize the affirmation of rights as a political process marked not only by advances, but by resistance and deep challenges.

KeyWords: Rights of women and girls; public policy; treaties and conventions; feminist movements.

\section{Introdução}

A segunda metade do século $\mathrm{XX}$, mais especificamente a década de 60 e parte dos anos 70, caracterizou-se por intensas mobilizações sociais que tiveram como efeito o alargamento do campo político nos países do Norte Global. Contradições sociais, altamente evidenciadas em um contexto de esgotamento do modelo fordista nos países centrais, propiciaram a emergência de novos movimentos sociais que reivindicavam outras formas de exercício do poder, críticas tanto ao capitalismo quanto ao socialismo real. As manifestações se espalharam por diversos países do mundo e significaram a emergência de novas subjetividades e estratégias de organização política (CARDOSO, 2005). Esse período foi um marco para os movimentos sociais e, em especial, para o feminismo.

Nesse momento, as lutas das mulheres já estavam em curso. Desde o século XIX, com as revoltas do operariado e o movimento sufragista, os princípios de liberdade e igualdade de oportunidades difundidos pelas revoluções burguesas passaram a ser exigidos pelas mulheres, geralmente excluídas dos processos de efetividade desses direitos. Assim, as primeiras pautas desses movimentos apresentavam reivindicações por melhores condições de trabalho - salário, redução da jornada e salubridade, e pela conquista de direitos políticos - de votar e representar interesses nos parlamentos.

No Brasil, onde o direito ao sufrágio universal ocorreu em 1932, os movimentos feministas careceram de maior destaque até o processo de redemocratização pós-ditadura militar. 
Nesse contexto, movimentos de mulheres atuaram na luta pela anistia e pela redemocratização. Desde 1970, o movimento feminista expandiu-se consideravelmente no Brasil, abordando temáticas relacionadas à sexualidade, direitos sociais e violência contra a mulher.

Os anos 1970 foram marcantes não apenas no Brasil, mas para o movimento feminista internacional. $\mathrm{O}$ fortalecimento das lutas das mulheres permitiu que 1975 fosse declarado o Ano Internacional das Mulheres, quando a Assembleia Geral da Organização das Nações Unidas organizou a Primeira Conferência Mundial sobre as Mulheres, na Cidade do México. Tal foi o impacto desse encontro que os anos de 1976 a 1985 compreenderam um período denominado "A década da mulher". Nesse momento, estabeleceram-se os alicerces de uma teoria feminista, destinada a compreender as origens e as causas das desigualdades entre os sexos. Atribuiu-se uma dimensão política ao problema da opressão feminina, da forma como propunham as feministas dos anos 60: "o pessoal é político"

\footnotetext{
${ }^{2}$ Dentre essas Convenções estão o Pacto Internacional de Direitos Civis e Políticos (1966), ratificado pelo Brasil em 1992; o Pacto
}

(LIPOVETSKY, 1997). Este foi um dos slogans mais importantes do feminismo na segunda metade do século XX, segundo o qual a sexualidade perde seu domínio eminentemente privado e passa a ser compreendida como uma relação de poder entre os sexos. A sexualidade teria, a partir de então, essência política, sendo constitutiva da ordem patriarcal.

(...) as feministas há muito tempo
reconheceram como imperativo o
trabalho de procurar, definir e
criticar a complexa realidade que
dirige nosso modo de pensar, os
valores que defendemos e as
relações que compartilhamos,
especialmente no que se refere ao
gênero. Se o contexto é o que
conta, o feminismo, em suas
diversas formas, está obrigado a
descobrir o que nos rodeia e a nos
revelar as relações de poder que
constituem as criaturas que vamos
ser. 'O pessoal é político' é o credo
desta prática com sentido crítico"
(DIETZ, 1999, p. 3 ).

No campo jurídico-normativo, já em 1948, a Declaração Universal dos Direitos Humanos havia assinalado a igualdade de direitos entre homens e mulheres. No entanto, avaliações posteriores identificaram lacunas na previsão e no cumprimento dos direitos humanos das mulheres. Por isso, na década de 60, um conjunto de Convenções Internacionais ${ }^{2}$, no âmbito

Internacional de Direitos Econômicos, Sociais e Culturais (1966), ratificado pelo Brasil em 1992; e o Pacto de São José da Costa Rica 
da Organização das Nações Unidas, passa a utilizar as categorias "homens" e "mulheres" para marcar a necessidade de se buscar efetividade nos direitos (BARSTED, 2001). Esses instrumentos legais, apesar de reconhecerem a titularidade das mulheres quanto aos direitos garantidos, não especificavam suas singularidades. No caso do Brasil, não houve impacto até os anos 1990, em virtude da ditadura militar que se instalara durante duas décadas.

Por esse motivo, em 1979, a forte pressão dos movimentos feministas de diversos países, articulados internacionalmente, resultou na Convenção das Nações Unidas sobre a Eliminação de Todas as Formas de Discriminação contra as Mulheres, concretizando os compromissos assumidos na Conferência realizada no México, em 1975. O Brasil tornou-se signatário dessa Convenção em 1981, embora com reservas no âmbito dos direitos civis. Em 1980, realizou-se a Conferência Mundial sobre a Mulher, em Nairobi, que traçou metas e ações concretas para superar as desigualdades de gênero e proporcionar o desenvolvimento das mulheres. Em
1993, a Conferência Mundial dos Direitos Humanos, realizada em Viena pela ONU, reconheceu que a promoção e a proteção dos direitos humanos das mulheres devem ser prioritárias para a comunidade internacional, buscando garantir maior consistência e validade para a Declaração Universal dos Direitos Humanos, de 1948. Em 1994, a Organização dos Estados Americanos deu força de lei à Declaração sobre a Eliminação da Violência contra a Mulher, emitida em 1993. Assim surgiu a Convenção de Belém do Pará, que elabora, finalmente, um conceito de violência contra a mulher, definida como: “...qualquer ação ou conduta baseada no gênero, que cause morte, dano ou sofrimento físico, sexual ou psicológico à mulher, tanto no âmbito público como no privado". (BARSTED, 2001)

\section{Avanços Legislativos: a Atuação do} Movimento Feminista e de Mulheres

O percurso descrito acima marca os caminhos percorridos pelo movimento feminista a partir dos anos 1960 que caracterizam a introdução da 
perspectiva de gênero na legislação internacional. Além disso, essa narrativa explicita a adoção de uma estratégia dos movimentos feministas que direciona parte significativa de seus esforços e de suas lutas para a arena jurídica e internacional. A adoção dessa estratégia, com impactos sensíveis na definição do feminismo contemporâneo, enseja uma série de questionamentos que podem ser desenhados como problemas sociológicos e passíveis de análise e compreensões mais aprofundadas.

A análise da articulação dos feminismos no âmbito internacional contribui para compreender a atuação transnacional das ativistas, bem como os limites dessa atuação, considerando a diversidade cultural e as dificuldades para a implementação das diretrizes internacionais nas legislações nacionais.

Reformas legais progressivas vêm alterando as relações sociais, sobretudo no que diz respeito aos direitos civis e políticos. A vedação às práticas discriminatórias vem garantindo a inserção maciça das mulheres nas mais diversas categorias profissionais, bem como os direitos relacionados com a maternidade e a proteção contra o assédio sexual. As mulheres representam, atualmente, $48,5 \%$ da força de trabalho mundial, ainda que persistam relevantes desigualdades de gênero, como maior propensão ao desemprego, à desigualdade salarial, à discriminação e ao trabalho informal (OIT, 2018). A despeito disso, o empoderamento econômico das mulheres se evidencia em países das mais diferentes culturas, produzindo avanços significativos na garantia e na efetivação dos direitos civis, sociais e políticos (ONU MUJERES, 2011).

Apesar dos relativos avanços no campo das políticas sociais, a violência contra as mulheres tem se caracterizado como uma constante nas relações entre homens e mulheres dos mais diversos países, faixas etárias, escolaridades e classes sociais. Tal fenômeno, historicamente indeterminado, não se restringe a certos modos de produção social ou arranjos culturais. Como “categoria polissêmica e multicausal",

a violência contra a mulher constitui-se em um fenômeno social persistente, multiforme e articulado por facetas psicológica, moral e física. Suas manifestações são maneiras de estabelecer uma relação de submissão ou de poder, implicando sempre em medo, isolamento, dependência e intimidação para a mulher. É considerada como uma ação que envolve o uso da força real ou simbólica, por parte de alguém, com a finalidade de submeter o corpo e a mente à vontade e 
liberdade de outrem". (BANDEIRA, 2014, p. 460)

A elaboração conceitual do fenômeno da violência contra as mulheres começou a ocorrer tardiamente, ganhando importância apenas na segunda metade do século XX. As primeiras publicações que versam sobre o tema, datadas dos anos 1960, tratavam da "violência intrafamiliar" e não individualizavam a mulher no contexto da violência (SCHRAIBER et. al., 2005). Somente nos anos 1970, o movimento feminista internacional passou a denominar o fenômeno de "violência contra a mulher", que especifica a mulher na relação interpessoal violenta e não restringe as situações ao âmbito familiar e doméstico, permitindo que o problema seja compreendido em dimensão mais ampla, que engloba assédios sexuais, tráfico de mulheres, estupros por estranhos, prostituição forçada, etc. "A partir desse momento, os estudos buscam apontar para a violência como um problema dos direitos da pessoa, fazendo que ganhe visibilidade e seja estudada no campo do direito". (SCHRAIBER et. al., 2005, p. 30)

Tendo em vista a necessidade de se ampliar o respaldo legal para as ações destinadas ao enfrentamento à violência contra as mulheres, nas últimas décadas, têm emergido, em diversos países por todo o mundo, instrumentos legais específicos. Nos anos recentes, a maior parte dos estados nacionais tem avançado no sentido de aprovar leis com o objetivo de reduzir as ocorrências de violência contra as mulheres. Atualmente, 125 países possuem legislações destinadas a essa finalidade, o que representa mais de $2 / 3$ dos 186 países signatários da Convenção sobre a Eliminação de todas as formas de Discriminação contra a Mulher CEDAW (ONU MUJERES, 2011).

No caso brasileiro, a especialização legal, ocorrida em 2006, quando foi promulgada a Lei Maria da Penha, resultou das articulações feministas que, há pelo menos duas décadas, reivindicava avanços nesse aspecto. Essa articulação deu-se, especialmente, a partir do Consórcio de ONGs (CEPIA, CFEMEA, AGENDE, ADVOCACI, CLADEM e Themis) que atuou, entre 2003 e 2006, tanto na elaboração de um projeto de lei, como no processo legislativo que culminou na promulgação da Lei Maria da Penha. Além disso, a LMP derivou da resposta à recomendação da Organização dos 
Estados Americanos que puniu o Estado brasileiro em virtude das omissões praticadas no caso de Maria da Penha. Logo, a institucionalização da violência contra a mulher, no Brasil, está imbricada com o panorama internacional, na medida em que a emergência da legislação resultou da internacionalização de um conflito interpessoal ocorrido dentro dos limites da soberania do Estado brasileiro cujos instrumentos institucionais disponíveis naquele momento não foram capazes de resolver adequadamente o conflito em questão. O litígio envolvendo Maria da Penha na Comissão Interamericana de Direitos Humanos pode ser considerado um caso de "litígio estratégico", em que as cortes são acionadas com o objetivo de provocar mudanças sociais maiores do que a própria solução da lide. Buscase atingir, por meio de processos judiciais, efeitos mais duradouros, muitas vezes relacionados a alterações na legislação (GONÇALVES, 2013).

A crescente participação das mulheres na política pode explicar a emergência de legislações especiais que visem à garantia dos direitos das

\footnotetext{
${ }^{3}$ Em 2011, 28 países haviam alcançado ou superado o índice de $30 \%$ de representação parlamentar feminina e 19 mulheres figuravam
}

mulheres. Há um século, menos de dez países garantiam o direito ao voto para as mulheres. Nos dias atuais, praticamente todos os estados nacionais asseguram a participação política às mulheres e sua inserção nos parlamentos e nas chefias de Estado, embora não igualitária em relação aos homens, é significativa ${ }^{3}$.

Além disso, outras razões podem ser aventadas para explicar o processo de especialização legal dos crimes cometidos contra as mulheres, dentre os quais vale mencionar o aumento da visibilidade dos movimentos sociais e de sua capacidade de pressão estatal, assim como transformações nas pautas feministas. Alemany menciona que entre 1970 e 1980 as feministas da França “evoluíram da crítica do direito à reivindicação de leis" (2009, p. 272).

\footnotetext{
As feministas realizaram ao mesmo tempo estudos sobre a vida doméstica e no trabalho, a prostituição, o estupro, organizaram manifestações, iniciaram ações de apoio a mulheres estupradas e levaram o debate para o campo jurídico (...): tudo isso permitiu revelar publicamente a relevância do problema (ALEMANY, 2009, p. 272).
}

O problema de que trata a autora consiste justamente no aumento das 
notificações de homicídios e agressões praticados contra mulheres nos anos mais recentes, que ocorre a despeito dos avanços legais nas esferas cível, política e social. "A pesar del enorme progreso alcanzado en los marcos legales nacionles, regionales e internacionales, millones de mujeres del mundo afirman haber sufrido algún tipo de violencia en sus vidas"(ONU MUJERES, 2013, p. 8). A Organização das Nações Unidas estima que cerca de $70 \%$ das mulheres sofram algum tipo de violência ao longo de suas vidas.

A denominação "violência contra as mulheres" atribuída a um conjunto de atos de agressão física e moral que se dão no espaço doméstico e no âmbito das relações afetivas pode ser creditada às movimentações feministas dos anos $60 \mathrm{e}$ 70 (MACHADO, 2009). Algumas décadas depois, o enfrentamento a estes atos passou a receber resposta legal com o advento de uma série de leis especialmente na América Latina $\mathrm{e}$ Caribe. A definição conceitual constituise como pré-requisito necessário para a caracterização de determinadas práticas como crime.

Tais tipificações legais são o resultado das negociações e correlação de forças entre as propostas das movimentações feministas, sua repercussão nas sensibilidades das organizações internacionais no combate a este tipo de violência e nas sensibilidades nacionais: não só dos Poderes Legislativo e Jurídico, como dos Poderes Executivos em assinarem e ratificarem os Tratados e Convenções Internacionais referentes à eliminação de todas as formas de discriminação contra as mulheres e ao enfrentamento à violência contra as mulheres (MACHADO, 2009, p. 159).

A atuação dos movimentos feministas e a participação das mulheres na política (governos e parlamentos) favoreceu a dinâmica internacional dos direitos das mulheres, articulando agendas e tornando a violência contra a mulher um fenômeno global. Este fenômeno migrou, rapidamente, de um fato restrito ao ambiente doméstico e privado, para o espaço público que transcende as fronteiras nacionais. Muito recentemente, os governos e os parlamentos dos estados têm sido fortemente pressionados para a inserção de leis e políticas específicas para a defesa dos direitos das mulheres nas agendas nacionais. Há uma dinâmica global (governança global/ redes internacionais de políticas públicas) que impulsiona este processo.

$$
\text { Segundo Walby (2002), o }
$$
feminismo tem sido reformatado por meio de um discurso global de direitos 
humanos e um foco crescente nas intervenções estatais. Isso é resultado de uma transição dos regimes de gênero que mudam as oportunidades econômicas e políticas das mulheres. Além disso, a globalização tem facilitado o desenvolvimento de novos espaços, instituições e retóricas em que os direitos humanos universais são utilizados como “princípio justificador”.

Há duas mudanças fundamentais no feminismo do mundo ocidental contemporâneo, que têm facilitado a prioridade dada a argumentos baseados em direitos globalmente articulados juntamente com uma orientação crescente para o Estado. Essas mudanças são a transição no regime de gênero e uma globalização complexa (WALBY, 2002).

A transição no regime de gênero propicia oportunidades políticas que têm favorecido as demandas feministas, pois as mulheres estão sendo incorporadas aos governos, o que caracterizaria idealmente as democracias liberais. Nesse sentido, essa perspectiva permite questionar quais as implicações políticas no âmbito das demandas de gênero decorrentes dessa nova realidade.

A globalização, por sua vez, propicia uma nova concepção para as políticas feministas, expressas por mudanças na produção discursiva e na argumentação. Nesse contexto, a globalização é compreendida como um processo de aumento da densidade e da frequência das interações sociais internacionais ou globais em comparação com as nacionais ou locais. Isso não quer dizer que existe uma supraterritorialidade, o que subestimaria o caráter territorial dos processos globais. A globalização não tem homogeneizado o mundo, conforme Walby (2002), pois restam muitas diferenças entre os países. De todo modo, a globalização reestrutura oportunidades e recursos políticos de um modo complexo.

O reenquadramento do feminismo nos marcos dos direitos humanos apresenta desafios relacionados à diversidade, que tem sido compreendida como um dos principais temas sociológicos na contemporaneidade. Assim, torna-se fundamental, no contexto da globalização, teorizar sobre as diferenças entre as mulheres sem reificá-las e, ao mesmo tempo, percebendo os elementos comuns da questão das mulheres. Esse desafio tem alicerces nas teorias feministas contemporâneas. Parte delas 
deposita seu foco na "doxa da diferença”, com estudos que consideram as diversidades étnicas, religiosas $\mathrm{e}$ culturais, observando as particularidades dos países e grupos sociais. Outra parte, por outro lado, vem compondo uma nova onda na prática feminista internacional que partilha do discurso dos direitos humanos.

Vale ressaltar que global e universal são perspectivas teoricamente diferentes, muito embora se confundam nas práticas políticas internacionais, o que muitas vezes representa uma estratégia de legitimação das pautas feministas. O global teria um aspecto prático, especial e temporalmente definido. Castells reconhece a importância do global na definição de certos projetos políticos. Considerando que a sociedade em rede é global, o Estado dessa sociedade não funciona unicamente no contexto nacional. Ao contrário, participa de um processo coletivo de governação global, o que não requer a existência de um governo global, tampouco o pretende, pois:

...uma vez que a governação global de algum tipo é uma necessidade funcional, os estados-nação estão a encontrar formas de fazer a gestão conjunta do processo global que afeta a maior parte dos assuntos relacionados com a prática governativa. Para o fazer, aumentam a partilha de soberania enquanto continuam a agitar orgulhosamente as suas bandeiras (...) existem por todo o mundo uma série de associações entre estados, mais ou menos integradas nas suas instituições e nas suas práticas, que estruturam processos específicos de governação transnacional”. (CASTELLS, 2005, p. 25).

As articulações internacionais do movimento feminista formam o que se pode chamar de redes transnacionais de políticas públicas. A existência de uma comunidade política delimita a agenda política dos estados e dá forma a ela, uma vez que "na perspectiva societária e mobilizatória (...) as redes fortalecem-se como atores políticos transnacionais na defesa de políticas públicas" (FLEURY, 2005, p. 80). Essas redes transnacionais de formulação de políticas públicas representam a capacidade dos movimentos sociais e das organizações da sociedade civil de concretizarem as “intersubjetividades planetárias". Interessa observar, assim, o modo como os atores engendrados na rede buscam consensos, tratados e compromissos de atuação coletiva. Desse modo, a descrição de redes transnacionais de políticas pode considerar: nível de institucionalização (estável/ instável); número de participantes (restrito/ aberto); configuração das políticas 
(setorial/ transetorial); tipo de atores sociais envolvidos; função principal da rede e equilíbrio de poder (redes homogêneas/ heterogêneas). Esse método considera que a estrutura da rede delimita a lógica da interação entre seus membros (FLEURY, 2005).

Espaços transnacionais de articulação feminista podem ser compreendidos nos marcos do conceito de campo político (BOURDIEU, 1998). Entendido como "um campo de forças e como campo de lutas", permite identificar as relações sociais internas ao campo que o configuram e que geram produtos políticos. A dimensão do conflito, assim, pode ser analisada de acordo com a proposta de Pierre Bourdieu que considera as concorrências entre os agentes na luta pela definição política.

Reconhece-se que o feminismo foi o movimento social mais importante da segunda metade do século XX e esta atuação modificou a vida de gerações de mulheres, dos mais diversos segmentos sociais e raciais. No século XXI, o feminismo consolida-se como política de Estado, ao mesmo tempo em que se ampliaram os mecanismos de consulta e participação social na formulação de políticas públicas. Mas, a vida das mulheres e homens ainda não foram totalmente tocadas pelo ideário da igualdade e permanece como um desafio para as novas gerações (BANDEIRA; MELO, 2010, p. 41).

Formulação de Políticas Para Mulheres no SÉC. XXI: a Atuação dos Novos Movimentos Sociais

A série de mudanças experimentadas pelas sociedades contemporâneas desestabiliza interpretações difundidas no bojo da modernidade. Diante da diversidade de lógicas de ação social causada pela aprofundamento de condutas pautadas na individualidade, novas interpretações emergem para dar conta da fragmentação e da pluralidade.

O conceito de "experiência social" surge nesse contexto de significativas transformações na relação entre sujeito e sociedade. A ideia de experiência apresenta-se por meio de uma "Sociologia da Experiência", formulada por François Dubet (1994), que atribui ao estoque de experiência e de conhecimentos as noções de vivência compartilhada, intersubjetividade e construção coletiva do mundo. A experiência 
social é, de acordo com essa perspectiva, capaz de dar sentido às práticas sociais e designa "as condutas individuais ou coletivas dominadas pela heterogeneidade de seus princípios constitutivos e pela atividade dos indivíduos que devem construir o sentido de suas práticas no meio desta heterogeneidade (DUBET apud WAUTIER, 2003, p. 180).

No contexto democrático em que parte das demandas do movimento feminista foi contemplada, especialmente aquelas ligadas ao enfrentamento à violência doméstica contra as mulheres, a relativa permeabilidade do Governo Federal às demandas sociais acompanhou a expansão da arena pública. A institucionalização de formas organizativas e de uma série de reivindicações históricas foi paralela ao fortalecimento da pauta dos direitos das mulheres de um modo geral. As inúmeras marchas de mulheres ou protestos feministas ocorridas nos últimos anos (Marcha das Vadias, Greve Internacional de Mulheres, Marcha das Mulheres Negras, Marcha das Margaridas, dentre outras) representam um dos efeitos desse processo de visibilidade, que se percebe desde o começo deste século, mas que se aprofunda de fato, na presente década. Nesse processo, a própria referência ao termo "feminismo" ou "feminista" transitou entre esferas de sentido e atingiu outros setores sociais. De um espaço mais restrito à política e à academia, o termo penetrou, nos anos mais recentes, espaços midiáticos $\mathrm{e}$ camadas significativas da juventude, especialmente a universitária.

Vale salientar que o aumento da aceitação do "feminismo" como terminologia coincide com uma ampliação bastante significativa do número de vagas nas universidades públicas na última década, o que pode ser uma chave explicativa para a profusão de ideias progressistas entre pessoas jovens. Muitos coletivos feministas têm nas universidades seu principal espaço de articulação, onde a despeito da persistência de relações assimétricas e da ocorrência de episódios de violência (BANDEIRA, 2017), há oportunidades ampliadas de discussão sobre questões de gênero e raça, autonomia individual, diversidade sexual e outros debates políticos com recorte interseccional.

A última década foi marcada por incremento significativo de pessoas com acesso à Internet no Brasil. Entre 2005 e 
2015, o percentual de domicílios com Internet saltou de $13,6 \%$ para $57,8 \%$ (EXAME, 2016). Ainda que este percentual seja considerado baixo considerando os parâmetros internacionais, outro fator faz com que o número de pessoas que acessam à Internet não dependa exclusivamente da disponibilidade de computador em casa. Trata-se do acesso à Internet por meio do telefone móvel, os smartphones. Os planos de dados e conexão atuais, mesmo aqueles de mais baixo custo, permitem acesso ilimitado às redes sociais, como Facebook, Whatsapp, Twitter e Instagram. Esses espaços virtuais têm larga adesão no Brasil, que figura dentre os países com maior número de usuários de redes sociais no mundo. Apenas do Instagram (que pertence ao mesmo grupo econômico que o Facebook) são 50 milhões de usuários brasileiros (FOLHA, 2017). No Facebook, dos 2 bilhões de usuários no mundo todo, 117 milhões são brasileiros (TECHTUDO, 2017).

Referindo-se especialmente à Primavera Árabe, mas englobando em

\footnotetext{
${ }^{4}$ Do original: "En todos los casos los movimientos ignoraron a los partidos políticos, desconfiaron de los medios de comunicación, no reconocieron ningún liderazgo y rechazaron
}

sua análise as grandes manifestações do séc. XXI, como o Occupy Wall Street, nos Estados Unidos Castells analisa a importância das redes sociais:

desde la seguridade del ciberespacio, gente de toda edad y condición se atrevió a ocupar el espacio urbano, en una cita a ciegas con el destino que querían forjar, reclamando su derecho a hacer historia - su historia - en una demonstración de la consciencia de sí mismos que siempre há caracterizado a los grandes movimientos sociales (CASTELLS, 2012, p, 20).

O autor identifica características semelhantes nos movimentos conectados pelo ciberespaço e destaca uma concepção peculiar de democracia.

\begin{tabular}{|c|}
\hline $\begin{array}{l}\text { Em todos os casos o } \\
\text { movimentos ignoraram o } \\
\text { partidos } \\
\text { desconfiaram dos meios díticos } \\
\text { comunicação, } \\
\text { reconheceram não } \\
\text { liderança e rechaçaran } \\
\text { qualquer organização formal } \\
\text { dependendo de Internet e de } \\
\text { assembleias locais para } \\
\text { debate coletivo e a tomada de } \\
\text { decisões (CASTELLS, 2012, } \mathrm{p} \\
\text { 21, tradução livre }{ }^{4} \text {. }\end{array}$ \\
\hline
\end{tabular}

Distintamente de interpretações pessimistas acerca dos novos movimentos sociais que os identificam

cualquier organización formal, dependiendo de Internet y de las asembleas locales para el debate colectivo y la toma de decisiones". 
com o aprofundamento do individualismo, em que ativistas seriam microcélulas com capacidade de penetração social muito limitada, Castells identifica nessas formas contemporâneas de atuação uma série de possibilidades comunicativas, capazes de integrar redes neuronais a redes de natureza e redes sociais. Essa forma de comunicação seria capaz, inclusive, de expandir as potencialidades da comunicação interpessoal. Além disso, ainda que cada um parta de significados próprios e interprete as informações recebidas de modo pessoal, há um condicionamento do processo mental pelo entorno social (CASTELLS, 2012). Isso quer dizer que as relações digitais estariam produzindo o contrário da atomização dos sujeitos políticos. Nesse mesmo sentido, Pierre Lévy destaca o caráter produtivo dos espaços de interação virtual:

Um mundo virtual, no sentido amplo, é um universo de possíveis, calculáveis a partir de um modelo digital. Ao interagir com o mundo virtual, os usuários o exploram e $\mathrm{o}$ atualizam simultaneamente. Quando as interações podem enriquecer ou modificar o

\footnotetext{
${ }^{5}$ Do original: "ejercen el contrapoder construyéndose en primero lugar a sí mismos mediante un proceso de comunicación
}

modelo, o mundo virtual tornase um vetor de inteligência e criação coletivas (LÉVY, 1999, p. 75).

Segundo Castells (2012) seria inclusive $o$ caso de perceber a emergência de companheirismo e novas dinâmicas de solidariedade política nesses redes, em que o exercício do contrapoder envolve mecanismos psicológicos de superação de medos e sofrimentos, o que é fundamental para enfrentar dinâmicas de violência e repressão. A maior parte dessas formas de atuação digital possui correspondência em formas de militância física, com estratégias de divulgação, formação política, propagação de interesses, atração de novos membros, reunião, enfrentamento, produção coletiva de ações. Mas os movimentos sociais contemporâneos "exercem o contrapoder construindo-se em primeiro lugar a si mesmos mediante um processo de comunicação autônoma, livre do controle do poder institucional" (CASTELLS, 2012, p. 27, tradução livre $)^{5}$. Desse modo, os novos movimentos sociais que se organizam

autónoma, libre del control del poder institucional". 
em redes digitais são capazes de produzir novos valores e transformar instituições sociais segundo princípios ressignificados que reorganizam a vida coletiva. É desse modo que um lugar simbólico pode vir a converter-se em um lugar público, um espaço de deliberação que, em última instância, constitui um lugar político que se destina a recuperar os direitos de representação outrora subtraídos por interesses dominantes.

Muito embora Castells (2012) assinale que, por essas razões, o Estado e os governos tendam a manifestar intimidação quanto às potencialidades de articulação política pelas redes sociais, parece subestimar a capacidade de coesão das elites políticas e das elites econômicas. Grandes grupos econômicos, dos quais fazem parte empresários e acionistas das principais organizações de comunicação virtual do mundo (que formam verdadeiros monopólios transnacionais), tendem a estabelecer relações de cooperação com os interesses de países de economia dependente do capital internacional volátil, como é o caso do Brasil. Por isso, é de se esperar que algoritmos, que definem nossas interações no espaço virtual, sejam definidos não apenas em consonância com interesses de interação pessoa a pessoa, mas com os interesses das grandes empresas - e dos governos que com elas estabelecem relações de dependência e colaboração.

Isso não significa que redes sociais não possam mesmo configurar "redes de esperança", em que poderão se desenrolar tramas de autorreflexão e identidades coletivas. $\mathrm{O}$ ponto de partida de uma estratégia política, aliás, pode ser uma emoção, positiva ou negativa. Nessas interações virtuais, desenvolvem-se sentimentos como inseguranças e desejos, que constituem o motor da ação política, segundo a teoria da inteligência afetiva mencionada por Castells (2012). As redes de esperança derivam, segundo o autor, da capacidade de imaginar o futuro, a partir da superação de ansiedades paralisadoras.

Há, na perspectiva de Castells (2012) sobre os novos movimentos sociais, significativas interconexões entre mente, corpo e política, o que contribui com a superação das dicotomias clássicas brevemente discutidas no primeiro capítulo deste trabalho. $\mathrm{O}$ autor rompe com as divisões entre subjetividade e objetividade na medida em que considera a ativação emocional e a experiência individual 
como base dos processos de comunicação.

A emoção tem sido crescentemente considerada nas perspectivas sociológicas que enfatizam a ação social. Impulsionadas por contextos políticos de efervescência cultural, as teorias que se empenham no desenvolvimento de uma sociologia das emoções reforçam a lógica não cognitivista e racionalista na produção dos sentidos da ação.

Novos movimentos sociais, desde a década de 70 do século $\mathrm{XX}$, desafiaram a ordem política vigente e minaram convenções adquiridas quanto ao estatuto social. Estes movimentos, que incluem os movimentos das mulheres, para a defesa do ambiente e pelos direitos dos negros, também contribuíram para a nova tomada de consciência quanto à importância da emoção nos processos sociais e culturais (BARBALET, 1998, p. 41)

É bem verdade que a ação política não decorre automaticamente desse processo em que emoções e experiências vêm à tona. "Para isso, se requer um processo de comunicação de uma experiência individual aos demais. Para que um processo de comunicação funcione, há dois requisitos: a consonância cognitiva entre emissores e receptores da mensagem e um canal de comunicação eficaz" (CASTELLS, 2012, p. 31).

Essas perspectivas respondem a análises das dinâmicas políticas atuais que tendem a sobrestimar formas de articulação tradicionais ou mesmo de negar a existência de formas alternativas de produção de demandas. Lévi (1999) explica que não se trata de substituir as formas de democracia institucional, mas de incorporar outras formas de participação na política, o que pode ser entendido como uma expansão da esfera pública. Sobre as controvérsias sobre a democracia que essa perspectiva envolve, Lévy explica que:

\begin{tabular}{|c|}
\hline $\begin{array}{ll}\text { Para cortar } & \text { pela } \\
\text { imediatamente } & \\
\text { malentendidos } & \text { sobr } \\
\text { "democracia } & \text { elet } \\
\text { vamos esclarecer } & \text { nov } \\
\text { que não se trata de faz }\end{array}$ \\
\hline
\end{tabular}

No que diz respeito às marchas de mulheres, não se pode afirmar que 
emergem da atuação virtual, inclusive porque manifestações públicas são expedientes da política feminista e de mulheres desde antes do surgimento e da popularização da Internet.

Ocorre que as redes sociais conferem uma dinâmica distinta a esses movimentos, que se valem dessas plataformas para ampliar adesões, divulgar eventos e armazenar registros (especialmente fotografias). Perfis de coletivos feministas, organizações de mulheres e mesmo de eventos específicos tornam-se uma espécie de arquivo de imagens, a partir do qual podem-se estabelecer diálogos e outras trocas, mesmo após a realização do evento. Vale ressaltar que essas páginas estão hospedadas em redes sociais (ainda que algumas delas também tenham sites), o que dinamiza sobremaneira as interações. Não se trata de disponibilizar um email em um site de conteúdo fixo, pelo qual as pessoas poderiam se comunicar. Mas, em vez disso, realizase, nas redes sociais, comunicação permanente cujo conteúdo poderá ser alimentado coletivamente e muito mais facilmente partilhado.

Essas imagens "exercem um papel fundamental de identificação, divulgação ideológica e socialização de significados" (WELLER; BASSALO, 2011, p. 284), representam experiências de corporificação da política feminista e de mulheres. Esse processo refere-se às dinâmicas de ação política em que sujeitos corporificados constituem a si a ao mundo social, de forma intersubjetiva e posicionada por dimensões geopolíticas, de raça, gênero, classe e sexualidade. As imagens representam, como propôs Roland Barthes, a vida e a morte da ação pois, a um só tempo eternizam e revelam a fugacidade do tempo, ou seja, a incansável dinâmica das coisas. É por essa razão que Mannheim (1951) assinala que os estudos destinados à compreensão das visões de mundo precisam ser renovados a cada período, pois as interpretações são limitadas e influenciadas pela localização históricas das vivências e das próprias observações. De todo modo, imagens representam, como técnica, uma política de corporificação do gênero (CONNELL, 2016; PARKINS, 2009), de materialização dos corpos (BUTLER, 2002) e de visibilidade da experiência (SCOTT, 1998).

A partir da perspectiva fenomenológica de Merleau-Ponty, segundo a qual incorporação (que corresponde ao conceito de embodiment) 
é a base para experiências intersubjetivamente vivenciadas, há centralidade do corpo em toda e qualquer ação política. Segundo Parkins (2009), não é possível pensar em agência sem os corpos que, em sua dimensão histórica, discursiva (e geopolítica, como diria Raewyn Connell), são fundamentais para a articulação da dissidência política. A fim de evitar demasiadas abstrações, Parkins (2009) assinala que em diversas situações de luta feminista e pelos direitos das mulheres, o desempenho corpóreo foi imprescindível na ação política. Referindo-se ao movimento das sufragetes, que conquistaram o direito ao voto na Inglaterra, afirma que foi através de atrevidos atos de protesto que mulheres como Mary Leigh atraíram atenção ao comportamento e capacidade de seus corpos e, assim, contestaram a constituição do domínio político e a própria natureza da cidadania (PARKINS, 2009).

As reflexões de Wendy Parkins, manifestas em um artigo de título sugestivo - "Protesting like a girl: embodiment, dissent and feminist agency" (2009), partem de um dilema antecipado por Nancy Fraser, segundo a qual a agência feminista parte de duas possibilidades. $\mathrm{Ou}$ fundamenta-se em teorias que assinalam o caráter restritivo das estruturas e normas de gênero, e com isso minimiza as capacidades de resistência; ou busca-se retratar a agência das mulheres de forma tão potente que se corre o risco de subestimar o poder da subordinação (PARKINS, 2009). Diante disso, almejase uma posição que integre as duas perspectivas de gênero, considerando-o, a um só tempo, uma estrutura social (pautada tanto pela experiência da colonização como pela globalização), e uma potência para a ação social.

$\mathrm{O}$ gênero não envolve um diálogo, exterior ao tempo, entre o biológico e o simbólico. Envolve um vasto processo formativo na história, ao mesmo tempo criativo e violento, no qual corpos e culturas estão igualmente em jogo e são constantemente transformados, às vezes até sua destruição" (CONNELL, 2016, p. 34).

Esse processo formativo pode ser também caracterizado como agência, que ocorre sempre em contextos determinados e em dada conjuntura de poder e desigualdade. É por isso que “(...) estabelecer a agenda das mulheres é definir a sua margem de poder. Daí que não se pode falar de agência das mulheres e de agência feminista sem 
equacionar sua dominação, opressão e/ou desigualdade, e sem estabelecer as suas margens de poder (MAGALHÃES, 2002, p. 193). A agência requer, portanto, que a ação se dê nas e contra as estruturas, tendo sempre em vista que a autonomia e o poder de algumas mulheres pode assentar na opressão de outras: de mulheres negras, imigrantes, indígenas, agricultoras, lésbicas, das mulheres com deficiência.

A respeito da agência política, $o$ processo de corporificação ocorre em consonância com a ação de "poner el сиеrpo". Isso significa não apenas falar, pensar ou desejar, mas ser verdadeiramente presente e envolvida, colocar todo o ser (corporificado) em ação, ser afetada por uma causa social e assumir, corporalmente riscos, tarefas e demandas deste compromisso. Poner el cuerpo é parte do vocabulário de resistência na Argentina, e implica na importância dos corpos materiais na transformação das relações sociais e da história (SUTTON, 2007).

É bem verdade que nesses diferentes espaços circulam noções muito distintas sobre "feminismo" e "mulheres". Diante de importantes dilemas, considerar as experiências vividas emerge não apenas como uma política de corporificação e produção de demandas, mas como uma ética que parte da humanização de rostos $-\mathrm{e}$ corpos - não representados. Capturar sofrimentos e agências por meio de uma câmera, permite compreender sentidos invisibilizados de precariedade, para além das instituições e seus representantes (BUTLER, 2011). Para tanto, é preciso superar a posição de observadora a fim de que se possa ser efetivamente interpelada pelas imagens, ou por elas afetada, na acepção de Latour (2008). Além disso, questionar-se sobre qual a função narrativa das imagens permite concretizar a noção de gênero corporificado tanto em sua dimensão estruturante como em sua potência emancipatória.

Ainda assim, Butler (2011), a partir da ética da alteridade de Emmanuel Levinas, adverte que sempre resta algo de irretratável em nós. Para que a representação exprima o humano, ela deverá falhar e mostrar sua falha. Isso vale não apenas para as imagens de marchas e protestos públicos, mas para a presença de mulheres em espaços de poder e na absorção de suas pautas nas políticas públicas. Toda a representação implica em não representação, em invisibilidades irretratadas ou 
parcialmente retratadas. Esse paradoxo deve ser absorvido nas representações que realizamos a fim de que, em um projeto de democracia corporificada, nossos produtos culturais sejam efetivamente apreendidos, em sua dimensão mais humana e vulnerável.

\section{Considerações Finais}

A narrativa das realizações dos movimentos feministas e de mulheres na transição do século XX para o XXI contribui para situar as mobilizações contemporâneas em um contexto mais amplo de avanços e retrocessos políticos. Nesse processo, mulheres de diferentes gerações estiveram envolvidas, a partir de distintos olhares, na produção de um espírito do tempo voltado para a superação das assimetrias de gênero, raça/etnia e ao combate das desigualdades e, especialmente, da violência. As transformações sociais conquistadas neste período são interpretadas, para os efeitos deste artigo, como resultado de estruturas de oportunidades políticas das quais derivam as expressividades dos movimentos feministas e de mulheres na contemporaneidade. Foi no começo deste século que o feminismo teve suas pautas finalmente institucionalizadas no Brasil.

Parece importante assinalar os aspectos mobilizadores desse processo, relacionados à ascensão de governos progressistas não apenas no Brasil mas em diversos países da América Latina. Esse contexto configura-se como aquele em que há estruturas de oportunidades políticas positivas, em que a democratização do Estado acompanha a democratização do próprio espaço público. Isso significa que nessa conjuntura houve um processo crescente de reinvindicação de demandas, o que pode ser sintetizado como um período de emergência de novos direitos para novos sujeitos.

Após mais de uma década de políticas sociais em curso e de uma significativa permeabilidade para as demandas das mulheres, evidenciou-se a expansão dos "repertórios" políticos, promovidos, em parte, por mulheres que estavam fora da institucionalidade. Então, trata-se de um paradoxo democrático, em que a participação das mulheres no poder amplia oportunidades para outras formas de expressão, gerando tensões para a visibilização de outras pautas. 
A expansão das funções sociais do Estado gerou, no entanto, um outro tipo de consequência, em curso a partir de 2014 no Brasil, relacionada ao avanço do conservadorismo e ao aprofundamento das noções de Estadomínimo em setores das elites e das classes médias. Após o processo político vivenciado pela América Latina, onde as esquerdas de diversos países chegaram ao poder na virada do século, inicia-se uma nova onda de mudanças significativas no contexto das lutas sociais, em um ciclo que se abre nas Marchas de Junho e que representa a transição de um período democrático e de aprofundamento das demandas por políticas sociais para um período com elementos não democráticos e com algum viés autoritário, em que as questões de gênero, de sexualidade devem sofrer um refreamento significativo.

Ainda que o cenário seja incerto, a visibilização das experiências das mulheres no processo de corporificação dos feminismos contemporâneos parece ser uma estratégia relevante para, mais uma vez, politizar o pessoal e aquilo que tem sido ininteligível ou descartado pela racionalidade política tradicional.

\section{Referências}

140

ALEMANY, Carme. Violências. In: HIRATA, Helena (et. al). Dicionário crítico do feminismo. São Paulo: Editora UNESP, 2009.

BANDEIRA, Lourdes Maria. Violência de gênero: a construção um campo teórico e de investigação. Revista Sociedade e Estado, vol. 29, n. 2, maio/agosto, 2014.

BANDEIRA, Lourdes Maria; MELO, Hildete Pereira. Tempos e memórias: movimento feminista no Brasil. Brasília: Secretaria de Políticas para as Mulheres/Presidência da República, 2010.

BANDEIRA, Lourdes Maria. Trotes, assédios e violência sexual nos campi universitários no Brasil. Revista Gênero, v. 17, n. 2, 2017.

\section{BARBALET, J.M. Emoção, teoria social e estrutura social: uma abordagem macrossocial. Lisboa: Instituto Piaget, 1998.}

BARSTED, Leila Linhares. A resposta legislativa à violência contra as mulheres 
no Brasil. In: Violência de gênero. ALMEIDA, Suely (Org.). Rio de Janeiro: Editora UFRJ, 2007.

BARSTED, Leila Linhares. Os direitos humanos na perspectiva de gênero. I Colóquio de Direitos Humanos. São Paulo, 2001. Disponível em: < http://www.dhnet.org.br/direitos/textos/ a_pdf/barsted_dh_perspectiva_genero.p df>. Acesso em: 10.ago.2013.

BOURDIEU, P. O poder simbólico. Rio de Janeiro: Bertrand Brasil, 1998.

BUTLER, Judith. Vida precária. Contemporânea - Revista de Sociologia da UFSCAR. São Carlos, Departamento e Programa de Pós-Graduação em Sociologia da UFSCAR, n. 1, jan-jun, 2011, p. $13-33$.

BUTLER, Judith. Cuerpos que importan: sobre los limites materiales y discursivos del 'sexo'. Buenos Aires: Paidós, 2002.

CARDOSO, Irene. A geração dos anos de 1960: o peso de uma herança. São Paulo: Tempo Social. Vol. 17, n. 2, novembro, 2005.
CASTELLS, Manuel. A sociedade em rede: do conhecimento à ação política. Lisboa: Imprensa Nacional - Casa da Moeda, 2005.

CASTELLS, Manuel. Redes de indignación y esperanza. Madri: Alianza Editorial, 2012.

CERQUEIRA, Daniel; MARTINS, Ana Paula Antunes. A institucionalização das políticas públicas de enfrentamento à violência contra as mulheres no Brasil. Instituto de Pesquisa Econômica Aplicada, Nota Técnica n. 13. Brasília, 2015.

CONNELL, Raewyn. Gênero em termos reais. Tradução: Marília Moschkovich. São Paulo: Inversos, 2016.

DIETZ, Mary. O contexto é o que conta: feminismo e teorias da cidadania. In: Cidadania e feminismo. São Paulo: Melhoramentos, 1999.

DUBET, François. Sociologia da Experiência. Lisboa: Instituto Piaget, 1994. 
FLEURY, Sonia. Redes de políticas: novos desafios para a gestão pública. Revista Administração em Diálogo. São Paulo, n. 7, 2005.

GONÇALVES, Tamara Amoroso.

Direitos humanos das mulheres e a Comissão Interamericana de Direitos

Humanos. São Paulo: Saraiva: 2013.

LATOUR, Bruno. Como falar do corpo? A dimensão normativa dos estudos sobre a ciência. In: J. Nunes; R. Roque Objetos Impuros: Experiências em Estudos sobre a Ciência. Porto: Edições Afrontamento, 39- 62, 2008.

LÉVY, P. Cibercultura. São Paulo: Editora 34, 1999.

LIPOVETSKY, Gilles. A terceira mulher: permanência e revolução do feminino. Lisboa: Instituto Piaget, 1997.

MACHADO, Lia Zanotta. Onde não há igualdade. In: MORAES, Aparecida F.; SORJ, Bila (orgs.). Gênero, violência e direitos na sociedade brasileira. Rio de Janeiro: 7 Letras, 2009.

MAGALHÃES, Maria José. Em torno da definição do conceito de agência feminista. $x$ aequo, $\mathrm{n}^{\circ} 7,2002$, pp. 189198.

MANNHEIM, Karl. Sobre a interpretação da Weltanschauung. In: Sociologia do conhecimento. Vol. I. Rés: Porto, 1951a.

MARTINS, Ana Paula Antunes. O sujeito nas ondas do feminismo e o lugar do corpo na contemporaneidade. Revista Café com Sociologia, vol. 4, n. 1, jan-abr, 2015.

\section{ORGANIZAÇÃO INTERNACIONAL} DO TRABALHO. Perpectivas sociales y del empleo en el mundo: avance global sobre las tendencias del empleo feminine 2018. Disponível em: < http://www.ilo.org > Acesso em: 20.ago. 2018.

ONU MUJERES. En busca de la justicia. El progreso de las mujeres en el mundo 2011-2012. Disponível em $<$ http://progress.unwomen.org/pdfs/SPReport-Progress.pdf> Acesso em: 12.set.2013.

PARKINS, Wendy. Protesting like a Girl: Embodiment, Dissent and Feminist Agency. Feminist Theory, 2000. 
SCHRAIBER, Lilia Blima (et.al.).

Violência dói e não é direito: a

violência contra a mulher, a saúde e os

direitos humanos. São Paulo: Editora

Unesp, 2005.

SCOTT, Joan. A invisibilidade da experiência. São Paulo: Proj. História, n. 16, fev, 1998.

SUTTON, Barbara. Poner el Cuerpo:

Women's Embodiment and Political Resistance in Argentina. Article in Latin American Politics \& Society 49(3):129 $162 \cdot$ September, 2007.

WALBY, Sylvia. Feminism in a global era. Economy and society. Vol. 31, Number 4, November, 2002, 533 - 577.

WELLER, Wivian; BASSALO, Lucélia de Moraes Braga. Imagens: documentos de visões de mundo. Porto Alegre: Revista Sociologias, ano 13, n. 28, set-dez, 2011, p. $284-314$.

WAUTIER, Anne Marie. Para uma Sociologia da Experiência. Uma leitura contemporânea: François Dubet. Sociologias [online]. 2003, n.9, pp.174-214. 